Мария Кувекалович

Белградский университет

Филологический факультет

Кафедра славистики

marija.kuvekalovic6@yahoo.com
УДК 821.161.1-2.09"19"

https://doi.org/10.18485/slavistika.2020.24.1.17

Оригинални научни рад примљено 29.04.2020.

прихваћено за штампу 21.05.2020.

\title{
ГЕРОИ-УДАРНИКИ ПЛАТОНОВА НА ФОНЕ КУЛЬТУРНОЙ И ОБЩЕСТВЕННО-ПОЛИТИЧЕСКОЙ ЖИЗНИ СССР В 1930 ГГ. (НА МАТЕРИАЛЕ ПЬЕСЫ «ВЫСОКОЕ НАПРЯЖЕНИЕ»)
}

В настоящей статье рассматривается влияние советской власти на создание героев-ударников Андрея Платонова, а также формирование художественного единообразия в пользу идеологии, что лучше всего показано как в литературе, так и в плакатном искусстве, и в сфере кинематографа в период индустриализации страны.

Ключевые слова: советская власть, герои-ударники, индустриализация страны, плакатное искусство, художественное единообразие.

The paper discusses the influence of the Soviet government on the creation of the characters, shock-workers, in Platonov's creative work, as well as the problem of creating artistic uniformity for ideological purposes during the period of the country's industrialization, which was best shown in literature, but also in film and poster art.

Keywords: Soviet government, shock-workers, country industrialization, poster art, artistic uniformity.

Под влиянием больших политических перемен и ускоренного темпа индустриализации в СССР, господствующий в творчестве Платонова образ инженера резко меняется в произведениях 1930-х годов («Машинист» (1930), «Котлован» (1930), «Ювенильное море» (1930), «Первый Иван» (1930), «Высокое напряжение» (1931), «Впрок» (1931), «Хлеб и чтение» (1931)). Данные произведения, впоследствии определяющие Платонова как вредителя социализма, пишущего на тарабарском языке ${ }^{1}$, окажутся переломными в дальнейшей судьбе писателя, утверждающие окончательно и бесповоротно его положение в системе советских писателей. Созданию вышеуказанных произведений, в том числе и неоконченного сценария «Турбинщик», способствовали поездки Платонова в Ленинградский металлический завод крупного машиностроения им. Сталина весной 1930-го года, которые повлияли и на возникновение нового типа плато-

\footnotetext{
${ }^{1}$ В своей статье «Платонов и Сталин: диалоги на «тарабарском» языке», Евгений Добренко пишет следующее: «Среди замечаний Сталина на полях повести «Впрок» интереснее всего не брань не выбиравшего выражения вождя, но его возмущение языком Платонова: «Это не русский, а какой-то тарабарский язык». И действительно, здесь сталкиваются две грандиозные языковые проекции: публичная, явленная Сталиным, и платоновская - зазеркальная» (Добренко, 2017: 110-119). Также, по поводу повести Платонова «Впрок», Сталин в мае 1931-го года пишет редакции журнала «Красная новь» следующее: «Рассказ агента наших врагов, написанный с целью развенчания колхозного движения и опубликованный головотяпами-коммунистами с целью продемонстрировать свою непревзойденную слепоту» (Сталин 1999: 150).
} 
новского героя-ударника, способного круглосуточно и беспрерывно работать и отвечать требованиям советской власти. Н. Корниенко в комментариях к пьесе «Высокое напряжение» отмечает, что «в сентябре 1930-го года Российская ассоциация пролетарских писателей (РАПП) принимается постановление о призыве ударников производства в литературу и показе ударника производства как генеральной темы пролетарской литературы» (Корниенко 2011: 694). Также, в пользу установления гегемонии и литературно-идеологического единообразия, РАПП принимает решение о показе ударников, целью которого является не только воспевание героев первых пятилеток, но и побуждение к новому пролетарскому движению в литературе, в котором не хватает места для отсталых писателей, которые больше не оказываются в состоянии следить за быстрыми темпами развития страны. В своей работе «К Хронике работы над пьесой Высокое напряжение» Дарья Московская обращает внимание и на тот факт, что «по требованию РАПП в ОГИЗе создаются: «ударная серия», «Социалистическое строительство», очерковая серия «Борьба за промфинплан третьего года пятилетки»; устанавливается для поощрения авторов этих серий особая премия, инициируются поездки специальных ударных бригад писателей в краткосрочные (2-3 декады) и долгосрочные (3-6 месяцев) командировки по крупнейшим предприятиям, индустриальным стройкам, колхозам и совхозам» (Московская 2017: 417). Хотя идея включения писателей в производственный процесс датируется еще появлением первых производственных романов: «Доменная печь» (1925) Ляшкого, «Цемент» (1925) Гладкова, «Стройка» (1925) Пучкова, «Лесозавод» (1927) Караваевой, становится вполне понятным, что и

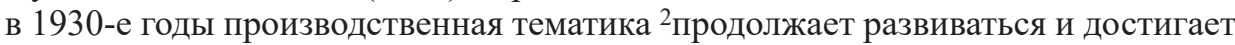
своего пика, как на фронте литературы, так и в сфере искусства, особо в сфере киноискусства. В этой статье мы постараемся разоблачить образы платоновских героев-ударников, их психологию и отношение к уже отстальлм инженерам старого поколения, а также попытаемся указать на развитие ударнической и производственной тематики в сфере фильмов, снятых в 1930-е годы.

В июне 1930-го года в рамках XVI съезда ВКП(б) Сталин пишет знаменательный «Политический отчет Центрального комитета», в котором заявляет, что «рост народного хозяйства идет у нас не стихийно, а в определенном направлении, а именно - в направлении индустриализации, под знаком роста удельного веса индустрии в общей системе народного хозяйства, под знаком превращения нашей страны из аграрной в индустриальную» (Сталин 2018: 189), в котором он одновременно восславляет труд и успех всех героев первого года пятилетки: «Самое замечательное в соревновании состоит в том, что оно производит коренной переворот во взглядах людей на труд, ибо оно превращает труд из зазорного и тяжелого бремени, каким он считался раньше, в дело чести, в дело славы, в дело доблести и геройства» (Сталин 1986: 200). Данной ста-

${ }^{2}$ К. Ичин в статье «Инженер в производственном процессе: Высокое напряжение А. Платонова» пишет, что «в 1919-м году была проведена первая конференция по художественной промышленности с требованием, чтобы мастерские согласовывали свою работу с фабриками. С этого момента образ художника-производственника начинает распространятсья на все сферы искусства с целью преодоления разрыва между искусством и трудом, с целью утверждения пролетарской культуры» (Ичин 2013: 101-102). 
тье предшествовала статья «Год великого перелома» (1929), в которой Сталин оптимистически смотрит в будущее, предлагая новый метод в борьбе за социализм и коллективизацию страны, а также способы осуществления генеральной линии коммунистической партии. Интересным для понимания духа эпохи является и «Договор о социалистическом соревновании обрубщиков трубного цеха» завода «Красный выборжец», опубликованного в марте 1929-го года в газете «Правда», бросающий вызов всем героям социализма: «Мы, обрубщики по алюминию, вызываем на социалистическое соревнование по поднятию производительности труда и снижению себестоимости» (Захарцев 2019: 36). Победители соревнования получали название «Ударник коммунистического труда». На фоне таких событий и новых постановлений власти СССР, Платонов через своих героев-ударников разрушает ложную утопическую картину советского быта, создавая настоящее представление о советском человеке в эпоху сталинизма, работающего под высоким напряжением. Одновременно он, как и его Машинист, задается вопросом: «Пронесемся или сгорим» (Платонов 2011: 462) в том ускоренном производственном процессе. Недаром Ханс Гюнтер в своей книге «По обе стороны от утопии» одну ее часть называет «Ювенильное море как пародия на производственный роман», утверждая, что «повесть на самом деле подрывает нормы этого жанра и продолжает критическую линию в творчестве Платонова» (Гюнтер 2011: 88). Приведенная мысль вполне применима и в контексте платоновских героев-ударников (Крашенина, Машинист, Девлетов....), которые парадируют и иронизируют требования советской власти к созданию нового утилитарного человека будущего, направленного только к строению социализма.

Образ героя-ударника лучше всего показан в пьесе «Высокое напряжение», в которой Платонов сравнивает и выделяет два типа инженеров - инженеров старого и инженеров нового ударнического поколения во главе с Крашениной. Образ женщины-ударницы сделан не случайно, а как раз со стремлением показать новое положение советской женщины, которая больше не только мать и хозяйка, но и носитель энергийного ударнического начала. Этот новый образ ударницы хорошо показан как в литературе, так и на плакатном искусстве СССР в 1930-е годы, особо в работах Страхова («Раскрепощенная женщина- строй социализм!»), Клуциса («Поднимая квалификацию работницы, помогаем ей стать активным и равноправным строителем новой жизни»), Пинуса («Делегатка, работница, ударница»), а также в работах Иорданского («Труженицы фабрик и полей, становитесь в боевые колонны ударниц!»), имеющие целью продвинуть как можно больше женщин к выполнению пятилетнего плана. Однако Мешков, инженер старого поколения, на слова Довлатова: «А вы будете теперь сменным инженером - вместе с Олей Крашениной» (Платонов 2011: 118), ${ }^{3}$ спрашивает даже с заметной обидой и удивлением: «Так я что же? Я мало способен или худ стал?» (118), а потом и замечает: «Я все понимаю. Я должен нести обязанности девушки» (118), что довольно четко выражает его сомнение по поводу такой возможности, чтобы Крашенина, как новый безопытный человек, могла работать лучше старого производственника. В отличие от отсталого, нико-

\footnotetext{
3 Здесь и дальше цит. по: Платонов А. П. (2011), Дураки на периферии. Пьесы и сценарии, (Москва: Время).
} 
му не нужного Мешкова, Крашенина, странное создание, которое, по словам Абраментова, одновременно спит и думает, является самым ярким представителем нового поколения. Платонов через образ Крашениной обыгрывает тему идеального, нужного человека, который все бригады, все механизмы видит во сне, но спит только нарочно, а таким образом жизни и приведет к единственной цели страны - победе социализма. Идеальный человек, как Крашенина, работает усиленно и бессменно по 20 часов, не чувствуя усталости и изнеможения. Жизнь вне завода для нового инженера-ударника практически не существует, о чем свидетельствуют слова ее мужа: «Спасибо тебе, жена... Две ночи я ждал тебя, сволочь» (123), и «Оля! Ты забыла меня, девочка?» (123) Это отчуждение, а также равнодушие ко всему, что не касается технического подъема и способов осуществления скорого прогресса и промфинплана, показана и на примере еще одного Машиниста-ударника, который на слова любимой девушки: «Я не знаю, зачем я ношу тебе еду и зачем тоскую, когда мы никогда не будем женаты» (463), отвечает спокойно и с уверенностью в конечной победе: «Уж скоро, Маша, будет социализм. Ты подожди чуть-чуть» (463), обещая ей, что «как социализм доделаем, так я тебя враз полюблю. А ты пока пойди походи». К. Ичин отмечает, что Платонов, «создавая образ Крашениной, бесспорно, имел в виду и действующее в то время постановление «О переходе на непрерывное производство в предприятиях и учреждениях СССР» (Ичин 2013: 106), которое устанавливало общий график работы. Согласно этому новому переходу, обеспечивается возможность ускорения выполнения пятилетнего плана, что, на самом деле, подразумевает бессменную работу на заводах и предприятиях. С другой стороны, даже когда ей предоставляется возможность не работать и отдохнуть, Крашенина спрашивает директора: «Как вам не стыдно? У меня новые молота на испытании» (143). Это возражение наводит на мысль, что для одного ударника отдых представляет собой самое страшное наказание, поскольку социализм их «ждать не будет» (129). Платонов, создавая образ Крашениной, имел в виду не только упомянутое постановление, но и, безусловно, знаменитую статью Горького («Ударники - в литературу»), впервые напечатанную в 1931-м году в журнале «Наши достижения», в которой автор указывает на роль и главную характеристику ударников: «Ударники, вырабатывая на практике, на живом опыте приемы трудовой дисциплины и экономии рабочей энергии, являются ведущей силою в области строительства социалистической промышленности и сельского хозяйства» (46). Именно поэтому вполне естественно, что беспартийные ударники так хорошо понимают смысл и значение генеральной партии и так охотно вступают в число ее членов, увеличивая ее, то есть свою творческую силу». Однако, Платонов в образе своего хорошо понимающего смысл и значение героя-ударника предупреждает о том, что он легко может превратить свое строительное начало в разрушительное, так как главным виновником случившейся катастрофы на заводе является не Почтальон, как это принято толковать, а именно она. Образ новой, по словам Мешкова и Жмякова, ненормальной жизни, от которой им хочется запла$\kappa a m b$, и есть настоящий «курс на катастрофу». Будучи техническим человеком, Платонов знал, что для новой жизни и ускоренной производительности, кроме нового человека, нужные и новые машины, которые будут сопутствовать темпу общего труда. Несомненно, это мнение разделяли и старые производственники, 
предупреждая о том, что, девочка «сгорит генератор», одновременно определяя ее решение включить тысячу киловатт как безумие, которое впоследствии стоило жизни Абраментову и Распопову. Смерть Абраментова и Распопова служит подтверждением того, что искусственное ударническое энергетическое начало, которым обладает Крашенина, «созидает социализм на гибели людей» (Ичин 2013: 109). Добавим к сказанному и описание из сценария «Машинист», подтверждающее предыдущую мысль: «Колхоз имени Генеральной Линии. Около некоторых изб стоят прислоненные новые тесовые гробы. У других изб мужики только делают гробы» (464). Недалеко от деревни видна железнодорожная дамба, пересекающая всю речную пойму поперек», из которого можно предположить, что мужики сознательно делают гробы для будущих жертв социализма, хотя данную сцену позволено трактовать и в духе федоровского учения.

Интересным для понимания психологии нового человека-ударника является и его отношение к машинам, а также отношение к производственникам старого поколения. Так например Крашенина на машину смотрит как на живое существо, нуждающееся в живых руках, в то время как мертвые руки Жмякова и Мешкова способны только умертвить это живое существо. Она даже явно обращается к машинам: «За кого, вы говорите, машины?» (130), на что получает ответ Пужакова: «За нас, Ольга Михайловна, — мы их заставим сочувствовать» (130). Таким образом, настоящий живой человек и машина меняются местами в миропонимании ударника. Чтобы спасти генератор, хотя неудачно, Крашенина пожертвовала жизнью Абраментова и Распопова и только в тот момент их жизнь приобрела некое значение. Над гробами умерших инженеров поставлена следующая надпись: «Два гроба на столах, два черных трупа в них. Два венка с надписями: Храбрейшему инженеру, товарищу рабочего класса, Другу Сене, павшему на поле пролетарской славы и чести. Общий транспарант над гробами: Мертвые герои прокладывают путь живым» (137). Платонов здесь, несомненно, издевается над существующими в то время лозунгами: «Труд в СССР есть дело чести, славы, доблести и геройства», «Ударный труд - дело чести», которые были широко использованы в качестве идеологического пропагандистского материала. Также, на наш взгляд, и в последнем предложении («Мертвые герои прокладывают путь живым») можно заметить насмешку над попыткой власти оправдать бессмысленную смерть Абраментова и Распопова перед другими инженерами, убеждая их в том, что их смерть - подвиг во имя будущего.

С другой стороны, образу ударницы противостоят образы представителей старого поколения инженеров - Жмякова и Мешкова, живущих в постоянном страхе не оказаться на хвосте общего темпа труда. Это чувство, несомненно, связано с так называемым «шахтинским делом» (1928), результатом которого власть обвинила «53 специалистов угольной промышленности в сознательном причинении вреда молодой советской экономике, а после непризнания ими своей вины - расстрел всех участников этого первого большого процесса» (Дужина 2010: 16). В подтверждение сказанному приведем слова Мешкова, произнесенные в момент происхождения аварии в компрессорной: «А?! Что в компрессорной? (Волнуясь.) А не говорили там, что меня нет?.. А я ведь спал, Сережа, я сильно сплю теперь. Я ударник и боюсь ослабеть, поэтому стараюсь лучше питаться, а по ночам не просыпаюсь» (116-117), из которых понятно, что 
предметом его волнения не является авария, а как раз тревога о том, чтобы ктото не обвинил его в вредительстве или связал с вредителями (недаром он спрашивает Абраментова: «А, Сережа, ты скажи мне тихо: ты не шпион, не подлец, не вредитель?» (115), а также: «А документы, Сережа, есть у тебя? Ты по закону вернулся в СССР?» (115)). Кроме страха, охватившего Мешкова, он чувствует себя ничтожным по сравнению с новым человеком: «Не знаю... Я слаб. Я вижу, что стал бездарен, что новые люди способней меня и знают уже больше» (118)). Это чувство и заставляет его думать о смерти, а также считать себя остатком от истраченной мелочи, которому нужно скончаться. Кроме того, Мешков - сирота, у которого нет своего класса, хотя Давлетов говорит о том, что «человек должен перестать быть сиротой» (118), а в том ему поможет социализм. Конечно, здесь Платонов иронически переосмысляет учение Федорова о необходимости соединения людей под общим делом. В данном случае, это общее дело - строение социализма, только усиливает чувство одиночества у всех героев, начиная с Мешкова: «никто ко мне в гости не приходит, и мне пойти некуда» (113) и Абраментова: «Теперь я одинокий»(117), «Я прожил жизнь в одиночестве, но умру в тесноте вашего класса» (130), заканчивая Крашениной, которая ни на что не жалуется, но все-таки своим образом жизни обречена на одиночество. Таким образом Платонов разрушает утопическое представление о социализме, предупреждая о том, что он своим искусственным напряжением только может привести к гибели людей и побудит их на вопрос, которым справедливо задается инженер Жмяков: «Боже мой, Боже мой, почто ты оставил меня... в таком веке?» (142)

Платонов, создавая образы ударницы и отсталого производственника некоторым образом ведет диалог со Сталиным по поводу статьи «Головокружение от успехов» (1930), которая была опубликована в марте 1930-го года. В данной статье Сталин пишет следующее: «Нельзя отставать от движения, ибо отстать значит оторваться от масс. Но нельзя и забегать вперед, - значит потерять связь с массами. Кто хочет руководить движением и сохранить вместе с тем связи с миллионными массами, тот должен вести борьбу на два фронта - и против отстающих, и против забегающих вперед» (Сталин 2018: 249). Как ответ на слова Сталина, Платонов на примере своих героев показывает, что человек, находящийся между стремлениями не отставать и не забегать вперед, теряет ясность ума (Крашенина) и желание жить (Мешков), что как раз и привело к катастрофе. Михаил Мухин в своей статье «Тактика индустриализации - ударники: нам денег не надо, талоны давай», пишет, что в 1932-м году основной проблемой не становится больше проблема отсталых инженеров, а проблема с лжеударниками: «Суть этого явления определить довольно сложно, так как нигде в документах четко не даются критерии отделения лжеударничества от ударничества истинного. Судя по всему, таковых критериев вообще не существовало, а призывы были отражением осознания заводоуправлением ненормальности ситуации». На фоне всего сказанного, платоновские герои справедливо задаются вопросом: «куда ж тут мне жить на этом свете?» (131)

Как уже было отмечено, ударническая тематика в 1930-е годы проникла и в сферу киноискусства. В газете «Известия» 11-го января 1929-го года опубликовано постановление секретариата ЦК ВКП(б) «О руководящих кадрах ра- 
ботников кинематографии», в котором определена, по мнению руководящей власти, главная цель киноискусства - «решительно бороться с попытками приспособления советского кино к идеологии непролетарских слоев», поскольку «кино является одним из важнейших орудий культурной революции и должно занять крупное место в работе партии, как могущественное орудие массовой агитации и пропаганды, коммунистического просвещения и организации широких масс вокруг лозунгов и задач партии и как средство для массового культурного отдыха и развлечения» (Яковлев 1999: 96). Помимо постановления ЦК ВКП(б), Дарья Московская отмечает, что в июне 1931-го года проходит Первый расширенный пленум правления МАПП, на котором была отмечена особая роль кино в осуществлении пятилетнего плана: «В прениях по докладу избранного генеральным секретарем МАПП В.М. Киршона в качестве важнейших для советского кинематографа были названы темы: показ-женщины-активистки на производстве и вредительство» (Московская 2017: 422). В данном пленуме одновременно была определена ключевая роль кино в борьбе за строение социализма. Здесь интересно упомянуть, что в том же году опубликовано «Постановление Политбюро ЦК ВКП(б) о желательности скорейшего возвращения С. М. Эйзенштейна в СССР» с целью, как впоследствии окажется, назначения его заведующим кафедрой режиссуры Государственного института кинематографии, а также с целью дальнейшего развития киноискусства в пользу идеологии.

Кроме «Симфонии Донбасса» Дзиги Вертова, представляющей собой «апофеоз индустриального труда, осуществляемого рабочим классом в деле построения социализма» (Ичин 2013: 108), в 1930-е годы на свете появлются следующие фильмы: «Земля» Довженко, «Не хочу ребенка» Галли, «Контакт» Косухина, «Песнь о первой девушке» Голуба и Садковила, «Ветер в лицо» Зархи а также фильм «Айна» Тихонова, сделан на основе сценария Платонова «Песчаная учительница» ${ }^{2}$. Все перечисленные фильмы, воспевающие ударнический труд и коллективное осмысление жизни, вполне вписывались в генеральную линию пролетарской кинематографии.

Особо следует обратить внимание на немой фильм «Земля» (1930), задуманный как последняя часть «Украинской трилогии». В данном фильме показана психология и отношение рабочих и крестьян к машине, а также их восхищение приездом трактора, предвещающего начало новой жизни. Надписи, показанные в фильме: «Будем здоровы с машинами», «Батько, теперь кулакам конец» и др., явно указывают на представление советского человека о возможности всеобщего спасения путем индустриального и технического развития. Группа крестьян поет песню о новой жизни, шагает стремительно за трактором, который их приведет к социализму, но все-таки они выглядят как группа гипнотизированных людей, блуждающих без определенной цели. Такая же ситуация встречается и в сценарии «Машинист»: на вопрос Чья ж теперь машина?, «Машинист отвечает с борта экскаватора: Ваша. Услышав это, весь колхоз в новой одежде берега бросается в воду. Достигнув экскаватора, люди хватаются за него и с жадно-

\footnotetext{
${ }^{4}$ Более подробно о том в: Р.Е.Климентьев, Работа А. Платонова в кино(1927-1930 г2.), Изв Сарат. ун-та. Нов. сер.Сер. Филология. Журналистика. 2018. Т. 18, вып. 3. 
стью держатся за причальные брусья. Лошади также подходят вброд к машине. Петух перелетает воду и садится на площадку понтона» (474). Эту человеческую жадность, которую справедливо можно считать и безумием, Довженко успел перенести на экран, обращая наше внимание на крупные глаза рабочих, охотно ожидающих спасение.

Проблема между двумя поколениями инженеров, на которую Платонов указывает в пьесе, обнаружена и в фильме «Конткак» (1930) Косухина. Представители нового поколения отказываются помочь старому, чтобы сохранить все плоды новой жизни только для себя. Такое поведение сурово осуждается и одновременно является причиной случившейся катастрофы, которая прямо отсылает к платоновской аварии, результатом которой произошла гибель Абраметова и Распопова.

С другой стороны, роль женщины как носителя энергийного ударнического начала, показана и в фильме «Песнь о первой девушке», которой удалось завести порядок и организовать сельсовет. Тематика данного фильма вписывается в картину советского быта и тенденцию продвижения женщин к выполнению пятилетнего плана.

Подводя итоги всему сказанному, следует отметить, что попытка власти интенсифицировать ударническую тематику была оценена Платоновым как попытка реализовать проект социализма насильственным и искусственным путем, в котором новый человек, в стремлении догнать и перегнать, теряется в этой сложной обстановке. Суть произведения правильно обнаружил цензор, скрывающийся под псевдонимом «Чекист», который выдвинул на первый план ряд ключевых вопросов, интересующих самого Платонова: «Почему так странно раскрыт инженер Абраментов, как от вредителя пришел он к подлинной любви к социализму, загорелся героическим энтузиазмом, жертвой которого он и пал? Наконец, почему мы так мало бережем людей, почему, действительно, наши достижения сплошь на жертвенности, а ведь именно под знаком жертвенности раскрывается вся пьеса» (Московская 2017: 426). Таким образом Платонов подчеркивает, что человеческая жизнь неоценима и что, на самом деле, промфинплан — это не бумага, это вот те люди, какие погибли (141) в ударническом производственном процессе.

\section{Использованная литература}

Григорьева, Надежда. Anima laborans: писатель и труд в России 1920-30-х гг. СанктПетербург: Алетейя, 2005.

[Grigor'eva, Nadezhda. Anima laborans: pisatel' i trud v Rossii 1920-30-kh gg. SanktPeterburg: Aleteriā, 2005.]

Гюнтер, Ханс. По обе стороны от утопии. Контексты творчества А. Платонова. Москва: Новое литературное обозрение, 2011.

[Giûnter, Xans. Po obe storony ot utopii. Konteksty tvorchestva A. Platonova. Moskva: Novoe literaturnoe obozrenie, 2011.]

Добренко, Евгений. Платонов и Сталин: диалоги на «тарабарском языке». «Страна философов» Андрея Платонова: проблемы творчества 8, 2017: 110-119.

[Dobrenko, Evgeni1̌. Platonov i Stalin: dialogi na «tarabarskom iāzyke». «Strana filosofov» 
Andreiā Platonova: problemy tvorchestva 8, 2017: 110-119]

Дужина, Наталья И. Путоводитель по повести А. П. Платонова «Котлован». Москва: Издательство Московского университета, 2010.

[Duzhina, Natal'iā I. Putovoditel' po povesti A. P. Platonova «Kotlovan». Moskva: Izdatel'stvo Moskovskogo universiteta, 2010]

Ичин, Корнелия. Инженер в производственном процессе: «Высокое напряжение» А. Платонова. Russian Literature LXXIII, 2013, 101-114.

[Ichin, Korneliiâ. Inzhener v proizvodstvennom protsesse: «Vysokoe napriāzhenie» A. Platonova. Russian Literature LKHKHIII, 2013, 101-114]

Малыгина, Нина М. Художественный мир Андрея Платонова. Москва: Московский педагогический университет, 1995.

[Malygina, Nina M. Xudozhestvennyı̌ mir Andreiā Platonova. Moskva: Moskovskiı̌ pedagogicheskiĭ universitet, 1995]

Московская, Дарья. К хронике работы над пьесой «Высокое напряжение». «Страна философов» Андрея Платонова: проблемы творчества 8, 2017: 416-447.

[Moskovskaiā, Dar'iā. K khronike raboty nad p'esoî «Vysokoe napriâzhenie». «Strana filosofov» Andreiā Platonova: problemy tvorchestva 8, 2017: 416-447]

Мухин. Михаил. «Тактика индустриализации»- ударники: нам денег не надо, талоны давай. < http://www.actualhistorru.ru> 15.08. 2019.

[Mukhin. Mikhail. «Taktika industrializatșii» - udarniki: nam deneg ne nado, talony davai. < http://www.actualhistorru.ru> 15.08. 2019]

Платонов, Андрей П. Дураки на периферии. Пьесы и сценарии. Москва: Время, 2011.

[Platonov, Andrě̆ P. Duraki na periferii. P'esy i stsenarii. Moskva: Vremiā, 2011]

Сталин, Иосиф В. Главные документы. Москва: Комсомольская правда, 2018.

[Stalin, Iosif V. Glavnye dokumenty. Moskva: Komsomol'skaiā pravda, 2018]

Яковлев, Александр Н. Власть и художественная интелигенция 1999: Документы ЦК РКП(б) - ВКП(б), ВЧК - ОГПУ - НКВД. О культурной политике 1917-1953 гг. Москва: МФД, 1999.

[IÄkovlev, Aleksandr N. Vlast' i khudozhestvennaiā inteligentsiiā 1999: Dokumenty TSK RKP(b) - VKP(b), VCHK - OGPU - NKVD. O kul'turnol̆ politike 1917-1953 gg. Moskva: MFD, 1999]

Марија Кувекаловић

\section{ЈУНАЦИ-УДАРНИЦИ ПЛАТОНОВА НА ПОЗАДИНИ КУЛТУРНОГ И ДРУШТВЕНО-ПОЛИТИЧКОГ ЖИВОТА 1930. ГОДИНЕ У СССР (НА МАТЕРИЈАЛУ ДРАМЕ „ВИСОКИ НАПОН”)}

\section{Резиме}

Рад разматра утицај совјетске власти на формирање јунака-ударника на материјалу Платоновљеве драме „Високи напон”, откривајући њено настојање да у идеолошке сврхе створи уметничку једноликост у свим областима уметности, посебно на пољу књижевности, плакатне уметности и филма. У својој драми Платонов на примеру Крашењине, активног 
јунака-ударника у борби за изградњу социјализма, као и на примеру Мешкова, представника старе генерације инжењера, покушава да разоткрије све облике новог живота који би требало да доведу до коначне победе социјализма. Ипак, ударнички рад у периоду индустријализације државе и прве петолетке, своју стваралачку енергију претвара у рушилачку, остављајући за собом само људске жртве, настрадале током рада под високим напоном. Такође, у раду је показана тежња совјетске власти да кроз плакатну уметност и филм насилним путем наметне модел новог живота, који подразумева ударнички темпо рада зарад будуће хармоније, што је, како се касније испоставило, довело до претварања једне утопистичке идеје у своју потпуну супротност.

Кључне речи: совјетска власт, јунаци-ударници, уметничка једноликост, плакатна уметност, филм. 